\title{
THE EFFECT OF ASCORBIC ACID ON RENAL FUNCTION IN DOGS WITH ISCHEMIA REPERFUSION INJURY
}

\author{
KISANI $^{1}$ A.I* and AKINRIMADE ${ }^{2}$ J.F \\ ${ }^{1}$ Department of Veterinary Surgery and Theriogenology, University of Agriculture, Makurdi \\ ${ }^{2}$ Department of Veterinary Surgery and Reproduction, University of Ibadan, Nigeria \\ *Corresponding author: E-mail: abohkisani@yahoo.com; Tel: +234 8033745806
}

\begin{abstract}
SUMMARY
The effect of ascorbic acid on renal function in dogs subjected to ischemia reperfusion injury was investigated. Six dogs with a mean weight of $10 \mathrm{~kg}$ (range $8-11 \mathrm{~kg}$ ) were used in the study. The dogs were administered ascorbic acid (treatment group) and the same volume of normal saline (control group).This administration was followed by reperfusion. Nephrectomy was carried out on the right kidneys. Blood samples were collected from these dogs post operatively on days 1, 3, 5, 7, 10, and 14 days and analysed for blood urea (BUN) and creatinine. There was no significant difference in serum creatinine level in both the control and treatment group ( $p>0.05)$. There was significant change in the levels of BUN in both the control and treatment groups $(p<0.05)$. In conclusion, ascorbic acid protects renal tissue from being damaged by ischemia-reperfusion injury, thereby, helping in the recovery of renal function.
\end{abstract}

KEY WORDS: Ischemia reperfusion injury, BUN, Creatinine, Ascorbic acid

\section{INTRODUCTION}

The occurrence of hemorrhage during and after surgical procedures is considered a complication which could affect the overall outcome of surgical interventions. During surgery, variety of measures are taken to prevent hemorrhage, prominent among which is the clamping of blood vessels. This cut off the blood supply to the tissues supplied by these vessels and creates ischemic injury. On restoration of blood supply to such tissues (reperfusion) more severe tissue injury occurs (Jefayri et al., 2000). The absence of oxygen and nutrients from blood creates a condition in which the restoration of circulation results in inflammation and oxidative damage through the induction of oxidative stress rather than restoration of normal function. This phenomenon has been shown to cause both local and systemic organ dysfunction (Fridovic, 1979).
Ischemia reperfusion injury is mediated by oxygen free radicals produced from the biochemical process which takes place when ischemic tissues are reperfused. The oxygen free radicals cause oxidative stress resulting in alterations in ability of the mitochondria to produce energy for the cells leading to a loss of cellular function and integrity (Sekhon et al., 2003). The damage of reperfusion injury is due in part to the inflammatory response of damaged tissues. White blood cells carried to the area by the newly returning blood release a host of inflammatory factors such as interleukins as well as free radicals in response to tissue damage (Wayne, 2005).

Renal graft rejection and renal failure are associated with ischemia-reperfusion injury (Jae-il et al., 2006a). Attempt to reduce the effect of this phenomenon is expected to improve the chances of survival of renal transplant patients. 
The aim of this study is to investigate the effect of antioxidant ascorbic acid pretreatment on the damage caused to the kidney by the induction of renal ischemia followed by reperfusion in a dog model.

\section{MATERIALS AND METHODS}

Six adult local (mongrel) dogs, purchased from Agbowo Market in Ibadan, with a mean weight of $10 \mathrm{~kg}$ (range, $8-11 \mathrm{~kg}$ ) were stabilized and subjected to renal function test were used for this study. The renal function test was performed by collecting urine sample through cystocentesis for urinalysis, and blood sample for creatinine and blood urea nitrogen analysis.

The animals were divided into two groups of three dogs each (treatment and control groups).

Group 1 (the treatment group) received ascorbic acid (an antioxidant) at 150 $\mathrm{mg} / \mathrm{kg}$ intravenously (i/v).

Group 2 (the control group) received equal volume of normal saline intravenously similar to the treatment group.

The dogs were pre-medicated with atropine sulphate at a dose rate of 0.04 $\mathrm{mg} / \mathrm{kg}$ body weight intramuscularly $(\mathrm{i} / \mathrm{m})$ and xylazine hydrochloride at a dose rate of $2 \mathrm{mg} / \mathrm{kg}$ body weight $\mathrm{i} / \mathrm{m}$. Anesthesia was induced and maintained with pentobabitone sodium ( $6 \%$ solution) at a dose rate of $10 \mathrm{mg} / \mathrm{kg}$ body weight $\mathrm{i} / \mathrm{v}$. All dogs were administered lactated ringers solution $10 \mathrm{mls} / \mathrm{kg} / \mathrm{hour}$ intravenously and ceftriaxone $(30 \mathrm{mg} / \mathrm{kg} \mathrm{i} / \mathrm{v})$ as a prophylactic treatment before surgery.

\section{OPERATIVE PROCEDURE}

For each experimental animal, the skin of the ventral abdomen was shaved, scrubbed and prepared aseptically using medicated soap (Dettol ${ }^{\circledR}$ soap) with water. The final scrubbing of the proposed surgical site was done using sterile gauze soaked in chlorhexidine solution.
The patient was anesthetized and placed on dorsal recumbency. Endotracheal intubation was effected and secured. Skin drapes and surgical incision drapes were placed on the animal. A ventral midline abdominal incision was made from the xiphoid process through the umbilicus to the pubis. The left kidney was exposed by packing the bowel loops to the right side of the animal using the mesentery of descending colon. The left renal artery and vein (of the left kidney) were exposed by removing fat covering the kidney; 150 $\mathrm{mg} / \mathrm{kg}$ of ascorbic acid was injected intravenously through the cephalic vein to the treatment group. After 10 minutes, the left renal artery and vein were clamped for 45 minutes after which the clamp was removed and blood flow to the kidney was restored. The right kidney was exposed by packing the intestinal loop to the left side of the animal using the mesentery of Ilium. The fat covering the kidney was removed. The renal artery was isolated and doubly ligated using 1-0 chromic catgut and transected. The vein was ligated and transected. The ureter was ligated and transected close to its insertion on the urinary bladder. Nephrectomy was affected.

The abdominal incision was closed in three layers. The linea alba was closed with chromic catgut size 1-0, using simple interrupted suture pattern. The subcutaneous tissue was closed with subcuticular suture pattern using chromic catgut size 3-0. The skin was closed with nylon size 1-0 using simple interrupted horizontal mattress suture pattern.

Blood samples were collected post operatively on days $1,3,5,7,10$ and 14 into blood sample bottles containing EDTA for blood urea nitrogen (BUN) and creatinine analysis using commercially available kit for the determination of the concentrations of blood urea nitrogen and creatinine in serum and plasma. 
The same procedure was repeated for the control group except that equal volumes of normal saline as the ascorbic acid used in the treated group were injected intravenously.

The mean and standard deviation for each experiment was determined using ANOVA and the student t-test. Differences at $\mathrm{p}<0.05$ were taken as statistically significant.

\section{POST OPERATIVE CARE}

The animals were returned to the kennels after recovering from anaesthesia and were allowed access to their normal ration of food and water.

Ceftriaxone was administered for 3 days at a dose rate of $30 \mathrm{mg} / \mathrm{kg} \mathrm{i} / \mathrm{m}$. Post operative pain was controlled with pentazocine (2 $\mathrm{mg} / \mathrm{kg}$ ) $\mathrm{i} / \mathrm{m}$ for three days. The skin sutures were removed on the ninth day post operatively.

\section{RESULTS}

All the dogs used (treatment and control) demonstrated good renal function. The serum creatinine and BUN levels were measured as indices of renal function. The mean serum creatinine levels in the control group increased to $1.8 \pm 0.2 \mathrm{mg} / \mathrm{dl}$ (base line levels $0.8 \pm 0.2 \mathrm{mg} / \mathrm{dl}$ ) after 5 days of reperfusion and then decreased gradually to $1.1 \pm 0.2 \mathrm{mg} / \mathrm{dl}$ by 14 days of reperfusion. The mean serum creatinine levels in the treatment group (base line levels $0.9 \pm 0.2 \mathrm{mg} / \mathrm{dl}$ ) increased to $1.7 \pm$ $0.1 \mathrm{mg} / \mathrm{dl}$ after 3 days of reperfusion and then decreased gradually to $1.1 \pm 0.1 \mathrm{mg} / \mathrm{dl}$ by 14 days of reperfusion (Figure 1). However, there was no statistically significant difference in the mean serum creatinine levels between the control and treatment group.

The mean serum BUN levels in the control group (base line levels $14.4 \pm 1.7 \mathrm{mg} / \mathrm{dl}$ ) increased significantly to $23.5 \pm 1.2$ by 14 days of reperfusion (Figure 2). The mean serum BUN levels in the treatment group (base line levels $14.9 \pm 1.3 \mathrm{mg} / \mathrm{dl}$ ) increased to $20.1 \pm 0.8 \mathrm{mg} / \mathrm{dl}$ after 3 days of reperfusion and then decreased gradually to $14.6 \pm 1.4 \mathrm{mg} / \mathrm{dl}$ by 14 days of reperfusion .There was statistically significant difference in the mean serum BUN levels between the treatment groups and the control $(\mathrm{p}<0.05)$.

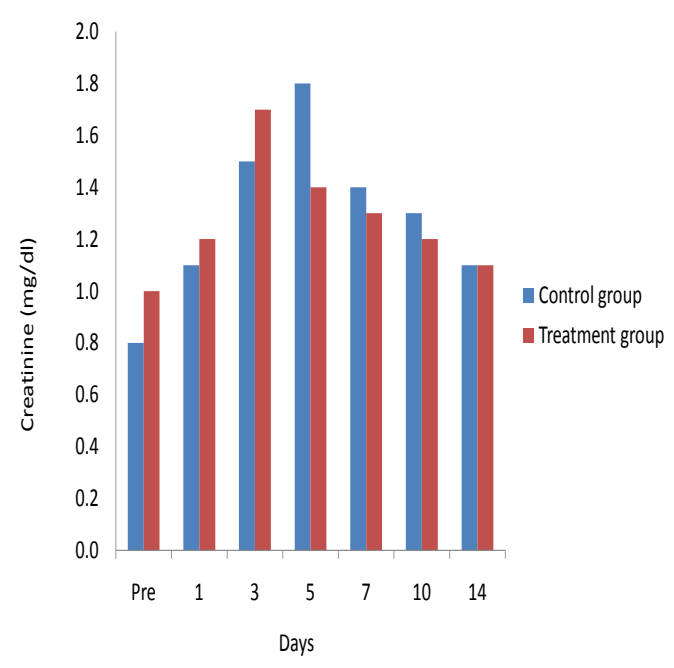

Figure1: Changes in creatinine concentration after renal ischemiareperfusion of kidneys subjected to 45 minutes of ischemia (values expressed as the mean with Standard Deviation).

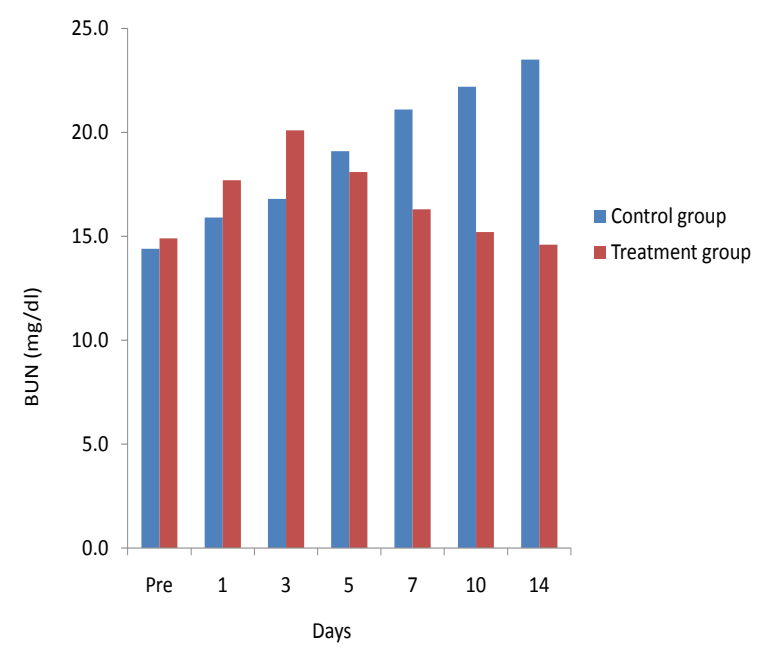

Figure 2: Changes in BUN concentration after renal ischemia-reperfusion of kidneys subjected to 45 minutes of ischemia 
(values expressed as the mean with

Standard Deviation).

\section{DISCUSSION}

In the present study the effects of ascorbic acid pre-treatment on the kidney damage after induction of renal ischemia followed by reperfusion was examined in dogs using changes in BUN and creatinine as indices of renal function.

Ascorbic acid, a water soluble antioxidant that reduces reactive oxidant radicals was used in an attempt to recover or mitigate the renal dysfunction by ischemia reperfusion injury. Changes of BUN and creatinine were evaluated following ischemia reperfusion injury.

Significant changes in BUN levels $(\mathrm{p}<$ 0.05 ) were observed in the control group when the pre-treatment and 14 days post treatment values, $14.4 \pm 1.7 \mathrm{mg} / \mathrm{dl}$ and $23.5 \pm 1.2 \mathrm{mg} / \mathrm{dl}$ respectively, were compared. In the treatment group, there was no significant difference between treatment and 14 days post treatment values $(14.9 \pm 1.3 \mathrm{mg} / \mathrm{dl}$ and $20.1 \pm 0.8$ $\mathrm{mg} / \mathrm{dl}$ respectively). These findings confirm that renal tissue damage has occurred due to ischemia-reperfusion injury and it is in agreement with the findings of previous authors-Sekhon et al. (2003) and Jae-il et al. (2006a).

The observed significant changes in BUN levels demonstrated in the control group was also in line with the findings of Sekhon et al. (2003) and Jae-il et al. (2006a). The reasons for these findings are most probably due to the greater and irreversible damages done to the distal segments of the proximal tubules as compared to the lesser and reversible damage suffered by the more proximal segments following ischemia reperfusion . The resultant necrosis at the proximal segments which is considered the basis for the decrease in the function as indicated by a significant increased in BUN levels.
In this study, the kidneys were subjected to 45 minutes of ischemia and ascorbic acid pre-treatment at a dose of $150 \mathrm{mg} / \mathrm{kg}$. Our findings compared favourably with that of Jae-il et al. (2006a) who also observed a significant but not abrupt increase in BUN levels in the control group 5 days post treatment. The severity of the changes in BUN levels demonstrated however, did not compare favourably with the findings of Sekhon et al. (2003) in which ischemia period of 90 minutes was used.

Serum creatinine levels were not significantly different in both control and treatment groups in this study. This is because it is possible that creatinine diffuses slowly than does BUN ( Jae-il et al., 2006a ) and its production is much more stable since it depends on intact muscles mass ( Michell, 1980 ). The production of creatinine is also not easily influenced by factors affecting urea formation (Osborne et al., 1972).

In conclusion, ascorbic acid has effect on renal tissue damage by ischemia reperfusion injury in protecting the tissue from the effect of ischemia reperfusion injury; This may be done by removing free radical intermediates and inhibit other oxidation reactions by being oxidized themselves to a stable and un-reactive form that do not cause cellular damage (Derek, 1996), thereby helping in the recovery of renal function. Also the use of BUN as an indicator for evaluating renal function in ischemia reperfusion injury could be taken to be reliable when compared to use of creatinine.

Forty-five (45) minutes of ischemiareperfusion appeared short for studies aimed at evaluating the influence of ascorbic acid on renal function. It is our opinion that longer period is used for further studies.

Also the influence of the long term post operatively administration of ascorbic acid 
needs to be studied. The prospect of the use of a higher dose of antioxidant to mitigate the effect of ischemia-reperfusion injury is also advocated.

\section{REFERENCES}

DEREK, D. (1996): "Vitamin C". Chemistry Review , 5 ( 5 ). University of York. http://www.search.com/reference/A scorbic_acid.

FRIDOVICH, I. (1979): Superoxide dismutases: Defence against endogenous superoxide radical, oxygen. Excerpta Medica, 77-93.

JAE-IL, L; HWA-YOUNG, S and MYUNG-CHEOL, K. (2006a):

Attenuation of ischemiareperfusion injury by ascorbic acid in the canine renal transplantation. J. Vet. Sci., 7(4): 375-379.

JAE-IL, L., MYUNG-JIN, K., CHANGSIK, P. and MYUNG-CHEOL, K (2006b): Influence of ascorbic on BUN, creatinine, resistive index in canine renal ischemia-reperfusion injury. J.Vet. Sci., 7(1): 79-81.

JEFAYRI, M.K., GRACE, P.A. and MATHIE, R.T. (2000):

Attenuation of reperfusion injury by renal ischemic preconditioning: The role of nitric oxide. BJU. Int., 85: 1007-1013.

MICHELL, A. R. (1980): The kidney: Regulation and disturbances of body fluids in: Physiological basis of small animal medicine eds. Yoxall A.T. and Hird I. F. R .: 7176.

OSBORNE, C. A., LOW, D.G. and FINCO, D. R. (1972): Canine and feline urology. W. B. Saunders, Philadelphia.
SEKHON, C. S., SEKHON, B. K., SINGH, I., ORAK, J. K. and SINGH, A. K. (2003): Attenuation of renal ischemia-reperfusion injury by a triple drug combination therapy. J. Nephrol., 16: 63-74.

WAYNE, M. C. (2005): Reperfusion injury in stroke. eMedicine . WebMD. Retrieve 2006-08-09. http://en.wikipedia.org/wiki/Reperf usion_injury 